\title{
Properties of Hooked Steel Fibers Reinforced Alkali Activated Material Concrete
}

\author{
M. A. Faris ${ }^{1, *}$, Mohd Mustafa Al Bakri Abdullah ${ }^{2,1}$, Khairul Nizar Ismail ${ }^{3}$, Ratnasamy \\ Muniandy ${ }^{4}$, Aiman Mahmad Nor ${ }^{2,1}$, Ramadhansyah Putra Jaya ${ }^{5}$ and Waried Wazien A. Z. ${ }^{2,1}$ \\ ${ }^{1}$ Center of Excellent Geopolymer and Green Technology, School of Materials Engineering, \\ University Malaysia Perlis, Perlis, Malaysia. \\ ${ }^{2}$ Faculty of Engineering Technology, Universiti Malaysia Perlis (UniMAP), Perlis, Malaysia. \\ ${ }^{3}$ School of Environmental Engineering, University Malaysia Perlis, Perlis, Malaysia. \\ ${ }^{4}$ Department of Civil Engineering, University Putra Malaysia, Selangor, Malaysia. \\ ${ }^{5}$ Faculty of Civil Engineering, Department of Geotechnics and Transportation, Universiti Teknologi \\ Malaysia, Johor Bahru, Malaysia
}

\begin{abstract}
In this study, alkali activated material was produced by using Class F fly ash from Manjung power station, Lumut, Perak, Malaysia. Fly ash then was activated by alkaline activator which is consisting of sodium silicate $\left(\mathrm{Na}_{2} \mathrm{SiO}_{3}\right)$ and sodium hydroxide $(\mathrm{NaOH})$. Hooked end steel fibers were added into the alkali activated material system with percentage vary from $0 \%-5 \%$. Chemical compositions of fly ash were first analyzed by using x-ray fluorescence (XRF). All hardened alkali activated material samples were tested for density, workability, and compression after 28 days. Results show a slight increase of density with the addition of steel fibers. However, the workability was reduced with the addition of steel fibers content. Meanwhile, the addition of steel fibers shows the improvement of compressive strength which is about $19 \%$ obtained at $3 \%$ of steel fibers addition.
\end{abstract}

\section{Introduction}

A new kind of materials with cement characteristics known as alkali activated material has been developed in recent years. The production of alkali activation material usually undergoes geopolymerization process where the glassy constituent was altered by a chemical process in well compacted and cement featured composites [1]. Alkali-activated material achieved excellent performance in many areas such fire and acid resistant, early mechanical strength, repairing materials, coating materials, and building materials. The development of alkali activated material as cement in building materials have been started since the 1940s [2]. Industrial trials have confirmed that these kind of materials is good and suitable to be used as cement in building materials [3]. Similar to OPC concrete, alkaliactivated material concrete also highly brittle which exhibit poor tensile strength. Many researchers have been done in order to improve the brittleness of alkali activated material

\footnotetext{
*Corresponding author: meorfaris88@gmail.com
} 
[4-6]. To improve the ductility, fibers inclusions in brittle alkali activated material matrix is an effective method to be applied.

The function of steel fibers is making a bridge between the cracks in the matrix and transfers the applied load to the matrix so that fiber reinforced concrete has better postcrack behavior than normal concrete [7]. The inclusions of steel fibers proved to increase the impact resistance and higher the flexural and tensile strengths [8]. P. S. Song et al. [9] and M. Valle et al. [10] conclude a few factors will enhance the properties of concrete including fiber volume, fiber surface bonding characteristics, and matrix strength. The inclusion of steel fibers was reported to improve the fatigue and dynamic resistance of OPC concrete through the high bond between steel fibers surface and cement paste that has been hydrated during the hardening process $[11,12]$. However, there has an issue that needs to consider with the additions of fibers which is the workability of OPC concrete will become lower. This low workability issue influence to higher the bleed water at the top of concrete [13]. However, detailed data regarding alkali activated material reinforced with steel fibers still less and need to be discovered more in order to strengthen the theory. Therefore, this paper goal to investigate the performance of alkali activated material with the additions of steel fibers which is hooked end steel fibers.

\section{Materials and Methodology}

Alkali-activated material concrete reinforced was produced by mixing between aluminosilicate raw material which is fly ash, alkaline activator, fine aggregate, coarse aggregate and fibers. Raw material (fly ash) was taken from Manjung power station, Lumut, Perak, Malaysia. This fly ash was identified as Class F according to ASTM C618 after chemical composition (Table 1) was analyzing by using XRF. According to chemical composition from Table 1, ratio between silica and alumina $\left(\mathrm{SiO}_{2} / \mathrm{Al}_{2} \mathrm{O}_{3}\right)$ of fly ash is 2.64 . Meanwhile, total composition of $\mathrm{SiO}_{2}+\mathrm{Al}_{2} \mathrm{O}_{3}+\mathrm{Fe}_{2} \mathrm{O}_{3}$ is $72.98 \%$ with the total $\mathrm{CaO}$ is equal to 18.10 .

Alkaline activator is consisting of a mixture between $\left(\mathrm{Na}_{2} \mathrm{SiO}_{3}\right)$ and $(\mathrm{NaOH})$. The $\mathrm{Na}_{2} \mathrm{SiO}_{3}$ obtained from South Pacific Chemicals Industry Sdn. Bhd. (SPCI), Malaysia with a ratio of $\mathrm{SiO} / \mathrm{Na}_{2} \mathrm{O}$ is equal to 3.2. Detail specification of $\mathrm{Na}_{2} \mathrm{SiO}_{3}$ is summarized in Table 2. Meanwhile, the $\mathrm{NaOH}$ pellet is obtained from Formosa Plastic Corporation, Taiwan with a concentration of $12 \mathrm{M}$ (after diluted with distilled water). Details specification of $\mathrm{NaOH}$ is summarized as in Table 3 .

Table 1. Chemical composition of fly ash.

\begin{tabular}{|c|c|c|c|c|c|c|c|c|c|}
\hline Component & $\mathbf{S i O}_{\mathbf{2}}$ & $\mathbf{A l}_{\mathbf{2}} \mathbf{O}_{\mathbf{3}}$ & $\mathbf{F e}_{\mathbf{2}} \mathbf{O}_{\mathbf{3}}$ & $\mathbf{T i O}_{\mathbf{2}}$ & $\mathbf{C a O}$ & $\mathbf{M g O}$ & $\mathbf{S O}_{\mathbf{3}}$ & $\mathbf{K}_{\mathbf{2}} \mathbf{O}$ & $\mathbf{M n O}$ \\
\hline $\begin{array}{c}\text { Percentage } \\
(\%)\end{array}$ & 38.80 & 14.70 & 19.48 & 1.02 & 18.10 & 3.30 & 1.50 & 1.79 & 0.16 \\
\hline
\end{tabular}

Table 2. Specification of $\mathrm{Na}_{2} \mathrm{SiO}_{3}$.

\begin{tabular}{|c|c|c|c|c|c|c|c|}
\hline Items & $\begin{array}{c}\text { Water } \\
\left(\mathbf{H}_{2} \mathbf{O}\right)\end{array}$ & Silica & $\begin{array}{c}\text { Sodium } \\
\text { oxide }\end{array}$ & $\begin{array}{c}\text { Viscosity } \\
\mathbf{a t ~ 2 0}^{\circ} \mathbf{C}\end{array}$ & $\mathbf{S i O}_{\mathbf{2}} / \mathbf{N a}_{\mathbf{2}} \mathbf{O}$ & $\begin{array}{c}\text { Molecular } \\
\text { weight }\end{array}$ & $\begin{array}{c}\text { Specific } \\
\text { gravity at } \\
\mathbf{2 0}\end{array}{ }^{\circ} \mathbf{C}$ \\
\hline Specification & $60.5 \%$ & $\begin{array}{c}30.1 \\
\%\end{array}$ & 9.4 & $0.4 \mathrm{~Pa}$ & 3.2 & $\begin{array}{c}122.06 \\
\mathrm{~g} / \mathrm{mol}\end{array}$ & $\begin{array}{c}122.06 \\
\mathrm{~g} / \mathrm{mol}\end{array}$ \\
\hline
\end{tabular}


Table 3. Specifications of $\mathrm{NaOH}$.

\begin{tabular}{|c|c|c|c|c|c|}
\hline Items & $\begin{array}{c}\text { Physical } \\
\text { form }\end{array}$ & Color & $\begin{array}{c}\text { Molecular } \\
\text { weight }\end{array}$ & $\begin{array}{c}\text { Water } \\
\text { solubility }\end{array}$ & $\begin{array}{c}\text { NaOH } \\
\text { content } \\
\text { (purity) }\end{array}$ \\
\hline Specifications & Pellets & White & $40 \mathrm{~g} / \mathrm{mol}$ & $100 \%$ & $>99 \%$ \\
\hline
\end{tabular}

Steel fibers used in this study were 3D Dramix Hooked end 80/60 BG produced by Bekaert which conforms to ASTM A820. The steel fiber dimensions and material properties are given details in Table 4 . The total amount of steel fibers additions were $0 \%$, $1 \%, 3 \%$, and $5 \%$ from the total weight of concrete.

Table 4. Properties of steel fibers.

\begin{tabular}{|c|c|c|c|c|c|c|}
\hline Items & $\begin{array}{c}\text { Fiber } \\
\text { type }\end{array}$ & $\begin{array}{c}\text { Diameter, d } \\
\mathbf{( m m )}\end{array}$ & $\begin{array}{c}\text { Length, } \mathbf{1} \\
\mathbf{( m m )}\end{array}$ & $\begin{array}{c}\text { Aspect } \\
\text { ratio, } \mathbf{1 / d}\end{array}$ & $\begin{array}{c}\text { Tensile } \\
\text { strength } \\
\left(\mathbf{N} / \mathbf{m m}^{\mathbf{2}}\right)\end{array}$ & $\begin{array}{c}\text { Young } \\
\text { modulus } \\
\left(\mathbf{N} / \mathbf{m m}^{\mathbf{2}}\right)\end{array}$ \\
\hline Specifications & Hook & 0.75 & 60 & 80 & 1.225 & 210 \\
\hline
\end{tabular}

Type of fine aggregate used in this experiment was river sand with a maximum size of $4.75 \mathrm{~mm}$. Meanwhile, coarse aggregate used was limestone with a maximum size of 20 $\mathrm{mm}$. A portion of fine aggregate used in this experiment was $730 \mathrm{~kg} / \mathrm{m}^{3}$, while coarse aggregate used were $1093 \mathrm{~kg} / \mathrm{m}^{3}$.

Sample cube of dimension $100 \times 100 \times 100 \mathrm{~mm}$ were cast for the production of alkali activated material concrete. Each sample was demoulded after 24 hours and cure at room temperature. After 28 days, all hardened alkali activated material samples were tested for density, workability, and compression. Workability was measured by slump test, while compression was conducted by using universal testing machine (UTS).

\section{Results and Discussions}

Figure 1 shows a result of density for different steel fibers addition starting from $0 \%, 1 \%$, $3 \%$, and $5 \%$. The density of all samples seems equivalent to that of conventional concrete which is around $2400 \mathrm{~kg} / \mathrm{m}^{3}$ [14]. Figure 1 shows alkali activated material concrete without steel fibers indicates the lowest density which is $2410 \mathrm{~kg} / \mathrm{m}^{3}$, followed by $1 \%$ of steel fibers addition $\left(2447 \mathrm{~kg} / \mathrm{m}^{3}\right), 3 \%$ steel fibers addition $\left(2461 \mathrm{~kg} / \mathrm{m}^{3}\right)$, and $5 \%$ of steel fibers additions shows the highest density $\left(2466 \mathrm{~kg} / \mathrm{m}^{3}\right)$. The additions of steel fibers seem slightly increase the density of alkali activated material concrete. 


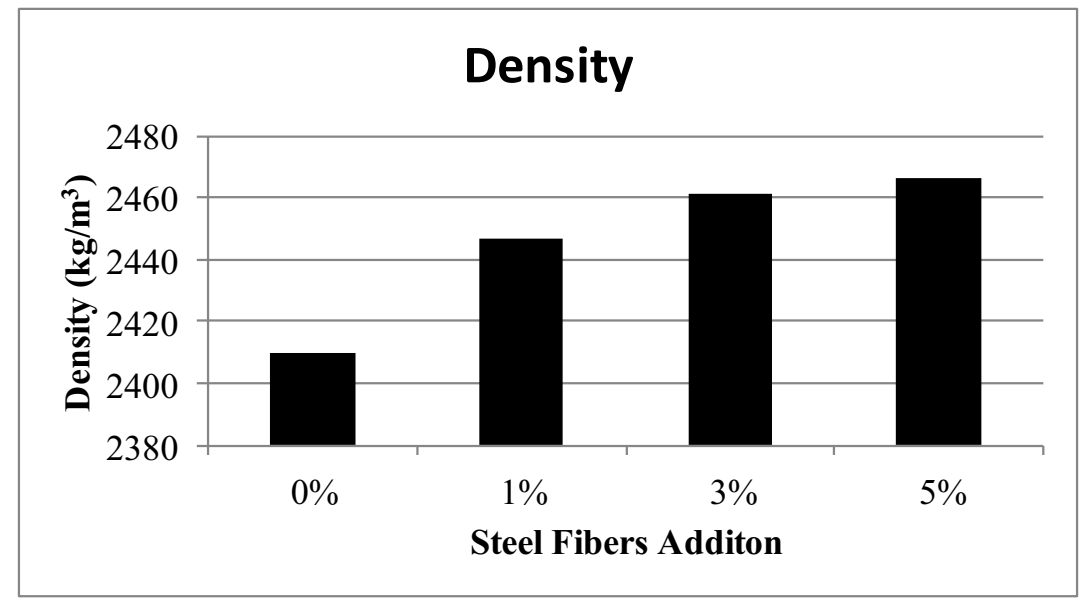

Fig. 1. The density of alkali activated material with the weight percentage of steel fibers addition.

Workability of alkali activated material concrete was measured in terms of a slump by using conventional slump cone apparatus. Slump test was conducted by following ASTM C143. All the mixtures were generally appeared cohesive and shiny due to the effect of reaction in the mixing of alkali activated material. Figure 2 shows the slump test result of alkali activated material concrete without steel fibers was $100 \mathrm{~mm}$. The slump of alkali activated material were decreased with the increasing of steel fibers addition which are 88 $\mathrm{mm}$ ( $1 \%$ steel fibers), $75 \mathrm{~mm}$ ( $3 \%$ steel fibers), and $55 \mathrm{~mm}$ (5\% steel fibers). This is shown that the existence of steel fibers will reduce the workability of alkali activated material concrete. The workability of concrete will significantly decrease due to increasing of friction between the steel fibers and the matrix where the fundamentally related theory have been clearly explained by Ranjbar et al. in their research of steel and polypropylene fiber reinforced geopolymer concrete [15].

The effect of steel fibers additions which are $0 \%, 1 \%, 3 \%$ and $5 \%$ to the compressive strength of alkali activated material concrete was plotted in a graph as in Figure 3. From the graph, $3 \%$ of steel fibers addition shows the highest compressive strength which is 69.40 $\mathrm{MPa}$, followed by $1 \%$ of steel fibers $(62.41 \mathrm{MPa}), 5 \%$ of steel fibers $(59.61 \mathrm{MPa})$, and the lowest value was $0 \%$ of steel fibers $(58.32 \mathrm{MPa})$. This result indicates the contribution of steel fibers addition in order to enhance the compressive strength of alkali activated material concrete. From the graph, the increasing of steel fibers additions will slightly increase the compressive strength of alkali activated material until reached $3 \%$ which is at the optimum value. 


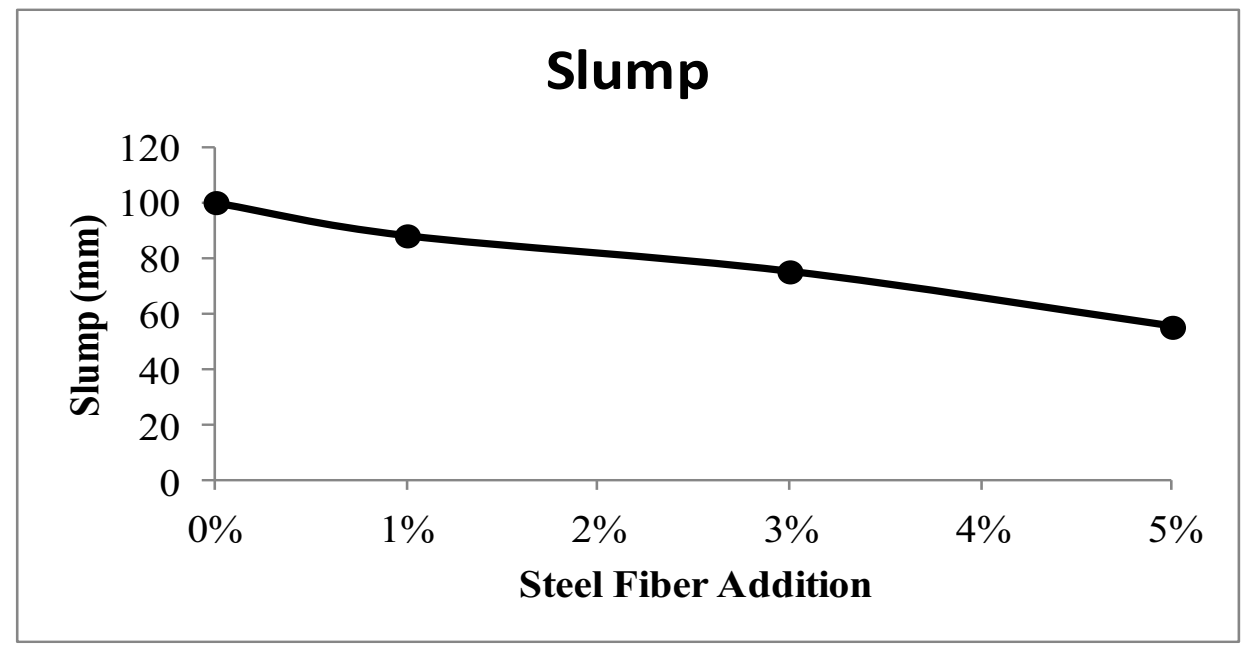

Fig. 2. Slump test of alkali activated material with the addition of steel fibers.

However, steel fibers addition higher than $3 \%$ indicates a reduction in terms of compressive strength. The increasing of compressive strength is due to the functioned of steel fibers addition to improved post-cracking behavior. This is supported by the previous researchers where Cuenca et al. conclude steel fibers act to bridge the crack spot if the total amount of steel fibers is sufficient [16]. The addition of steel fibers in alkali activated material concrete give minor effect to the enhancement of alkali activated material concrete which is about $19 \%$ increment at $3 \%$ steel fibers additions (optimum).

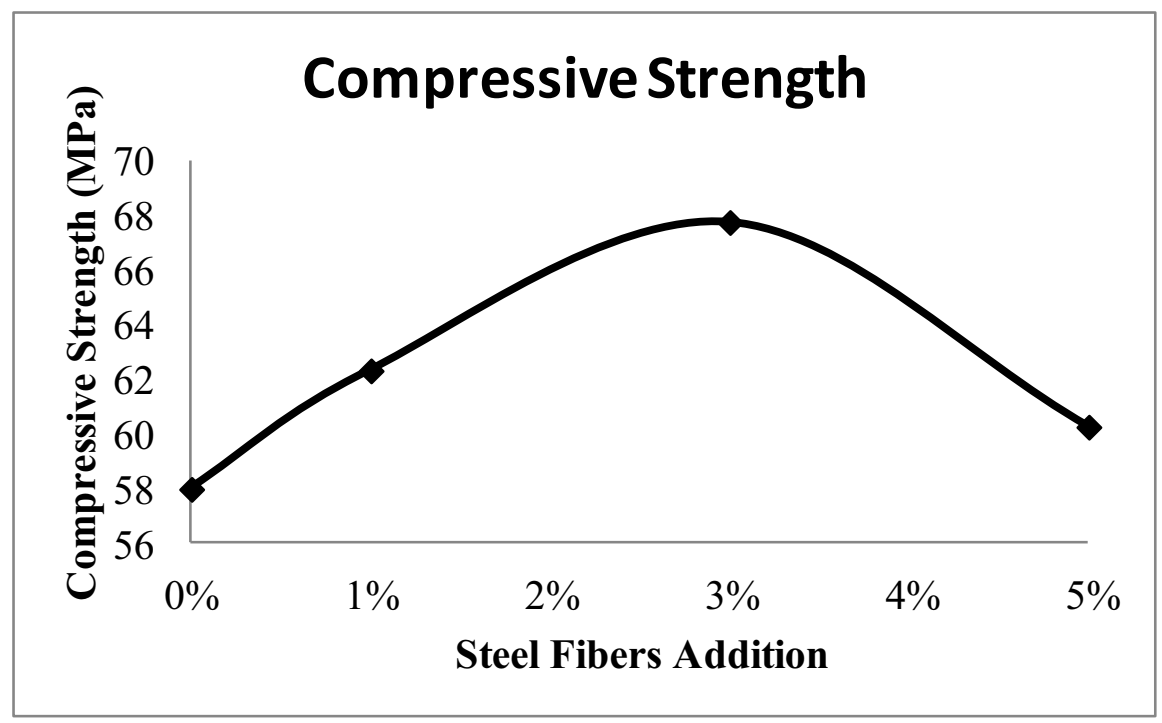

Fig. 3. Compressive strength of alkali activated material with the addition of steel fibers. 


\section{Conclusion}

The inclusion of hooked steel fibers doesn't give significant effect to the density of alkali activated material concrete. There is slightly increasing of density with the increasing of hooked steel fibers addition. Meanwhile, the inclusion of hooked steel fibers give influence to the workability of alkali activated material concrete where the addition of hooked steel fibers reduced the workability of alkali activated material concrete. Additions of hooked steel fibers improved the compressive strength until reached at optimum value which is at 3 $\%$ and over than that, the compressive strength slightly getting lower.

Authors gratefully acknowledge the financial support and facilities in order to complete this research provided by Centre of Excellent Geopolymer \& Green Technology (CEGeoGTech) and University Malaysia Perlis (UniMAP).

\section{References}

1. G. Gorhan, G. Kurklu, Compos. Part B-Eng., 58, 371 (2014)

2. M. Roy Della, Cement Concrete Res., 29, 249 (1999)

3. A. Fernandez Jimanez, A. Palomo, C. Lopez Hombradoz, ACI Mater. J., 2, 106 (2006)

4. S. Karunanithi, S. Anandan, Advances in Civil Engineering, 2014, 1 (2014)

5. A. Hutagi, R.B. Khadiranaikar, R. Shemblle, Journal of Civil Engineering Technology and Research, 2, 15 (2014)

6. J. Venkateswararao, R.K. Srinivasa, K. Rambabu, ARPN Journal of Engineering and Applied Sceience, 8, 800 (2013)

7. Y.Y. Lu, N. Li, S. Li, Constr. Build. Mater., 95, 74 (2015)

8. H.T. Wang, L.C. Wang, Constr. Build. Mater., 38, 1146 (2013)

9. P.S. Song, S. Hwang, Constr. Build. Mater., 19, 669 (2004)

10. M. Valle, O. Buyukozturk, ACI Mater. J., 90, 122 (1993)

11. S. Wei, G. Jianming, Y. Yun, ACI Mater. J., 93, 206 (1996)

12. W. Yin, T. Hsu, ACI Mater. J., 92, 71 (1995)

13. I. Topcu, V. Elgun, Cement Concrete Res., 34, 275 (2004)

14. R.C. Dorf, The Engineering Handbook, Second Edition (CRC Press New York, 2004)

15. N. Ranjbar, S. Talebian, M. Mehrali, Compos. Sci. Technol., 122, 73 (2016)

16. E. Cuenca, J. Echegaray Oviedo, P. Serna, Compos. Part B-Eng., 75, 135 (2015) 